\title{
Risk of Seizures after Endovascular Management of Ruptured Intracranial Aneurysms: A Systematic Review and Meta-analysis
}

\author{
Ezequiel García-Ballestas, MD ${ }^{1,2}$, William A Florez- Perdomo, MD ${ }^{1,3}$, \\ Robert M Starke, MD, MSc ${ }^{4}$, Andrei Fernandes Joaquim, MD ${ }^{5}$, Amit Agrawal, MD, MCH ${ }^{6}$, \\ Ravish Rajiv Keni, $\mathrm{DM}^{7}$, Luis-Rafael Moscote-Salazar, $\mathrm{MD}^{1,2}$ \\ ${ }^{1}$ Latin American Council of Neurocritical Care, Cartagena; ${ }^{2}$ Center of Biomedical Research (CIB), Faculty of \\ Medicine, University of Cartagena, Bolivar; ${ }^{3}$ Faculty of Medicine, Surcolombian University, Neiva, Colombia; \\ ${ }^{4}$ Department of Neurosurgery \& Neuroradiology, University of Miami \& Jackson Memorial Hospital, Miami, FL, \\ USA; ${ }^{5}$ Department of Neurosurgery, University of Campinas (UNICAMP), São Paulo, Brazil; ${ }^{6}$ Department of \\ Neurosurgery, All India Institute of Medical Sciences, Saket Nagar; ${ }^{7}$ Department of Neurology, Narayana Medical \\ College, Nellore, India
}

Received November 4, 2020

Revised November 26, 2020

Accepted December 4, 2020

Corresponding author:

Amit Agrawal, MD, MCH

Department of Neurosurgery, All India

Institute of Medical Sciences, Saket Nagar,

Bhopal, Madhya Pradesh 462020, India

Tel. +91-8096410032

E-mail; dramitagrawal@gmail.com or dramitagrawal@hotmail.com
Seizures in aneurysmal subarachnoid haemorrhage (aSAH) have been described secondary to SAH, changes in cortical function, vasospasm and as a result of treatment effects. Seizures are one of the important clinical determinants in neurological outcome of aSAH. Various studies support the notion of less risk of future seizures in endovascular treatment as compared to the microsurgical clipping, yet there is no conclusive evidence in favour or against the seizure occurrence in aSAH patients after endovascular treatment as compared to the microsurgical treatment. To carry out a systematic review and meta-analysis of the risk of seizures after endovascular management (coiling) of ruptured intracranial aneurysms. A literature search was performed in electronic database of PubMed, MEDLINE, Embase, and Scopus from inception to February 2020, using the terms Seizure, Intracranial aneurysms, embolization, with no constraints applied. Data were pooled using a random-effect model, results were abstracted as odds ratios (ORs) and 95\% confidence interval $(\mathrm{Cl})$, and heterogeneity was reported as Chi-square. Five studies involving 3,077 patients were included in the meta-analysis. After endovascular management of aSAH, seizure risk was increased by a worse clinical severity (World Federation of Neurosurgery scale or Hunt and Hess) (OR, 3.34; 95\% Cl, 2.69-4.16; $p<0.00001)$, severe vasospasm $(\mathrm{OR}, 2.20 ; 95 \% \mathrm{Cl}, 1.67-2.92 ; p<0.00001)$, cerebral infarction $(\mathrm{OR}, 5.19 ; 95 \% \mathrm{Cl}, 3.23-8.35$; $p<0.00001$ ), and cerebral edema (OR, 1.79; $95 \% \mathrm{Cl}, 1.37-2.34 ; p<0.0000)$. Worse clinical severity, vasospasm, cerebral infarction and cerebral oedema are significant risk factors for the development of seizures after endovascular intervention in $\mathrm{aSAH}$. The mechanism for this correlation is not clear. (2020;10:55-61)

Key words: Endovascular procedures, Intracranial aneurysm, Seizures

\section{Introduction}

Aneurysmal subarachnoid haemorrhage (aSAH) is a life-threatening neurological emergency. Recent evidence has shown promising advances in the last decade regarding this disease. In developed countries, the incidence of aSAH is estimated at 8-11 per 100,000 inhabits. ${ }^{1}$ aSAH results in increased intracranial pressure (ICP) in ap- proximately $70 \%$ of patients, with a mortality rate of about $30 \% .{ }^{2} \mathrm{~A}$ seizure is a potential complication after aSAH. In unruptured intracranial aneurysms, the risk of seizures is minimal but not absent. ${ }^{3}$ In contrast, subarachnoid haemorrhage due to aneurysm rupture may present with one of its fearsome complications, i.e., seizures. In general, the seizures in aSAH could be due to the natural history of the disease or iatrogenic due to therapeutic intervention. Studies have 
reported the incidence of seizures ranging from 4.95 to $21.2 \%$ and 0.7 to $10.7 \%$ for surgical clipping and endovascular coiling, respectively. ${ }^{4}$ There is also some evidence suggesting that seizure risk is higher with clipping, rather coiling. ${ }^{5}$ However, estimating the risk of seizure is not easy because of the high heterogeneity noted in different studies due to non-uniform study population, study design, intervention, and patient outcomes. Seizures are associated with acute neurological deterioration after an endovascular procedure, and recurrent seizures can transform into chronic epilepsy in the long-term with a subsequent disability in day-to-day activities. ${ }^{6}$ Therefore, we conducted a systematic review to assess the potential association of seizure and endovascular management of ruptured intracranial aneurysms and its risk factors.

\section{Methods}

This study followed the preferred reporting items for systematic reviews and meta-analyses (PRISMA) reporting guidelines and the meta-analysis of observational studies in epidemiology reporting guidelines.

\section{Search strategy}

We searched the electronic database of PubMed, MEDLINE (Ovid), EMBASE, and Scopus from inception to February 2020 for randomized clinical trials $(\mathrm{RCT})$, not $\mathrm{RCT}$, prospective and retrospective cohort studies that reported data on the risk of seizures after treatment of aSAH ( Supplementary Material 1). We added studies from the reference list of included studies and other relevant data in addition to potentially eligible studies.

\section{Eligibility criteria}

The studies to be included were screened separately using the following inclusion criteria: patients with aSAH and RCT, not RCT, prospective and retrospective cohort studies assessing the relationship between clinical and radiological characteristics to seizures in aSAH treated with coiling.

\section{Data collection process}

Two review authors (L.R.M.S. and W.F.P.) independently extracted data from the included studies using a piloted data extracted form, resolving any discrepancies through discussion. We retrieved any articles identified as potentially relevant by at least one review author.
Two review authors (L.R.M.S. and W.F.P.) independently screened full-text articles, with discrepancies resolved through discussion. The references of relevant studies were cross-checked for additional studies not identified by the electronic search.

\section{Data extraction}

The following data were extracted from the included studies: age (older than 50 years old), gender (female), clinic severity (World Federation of Neurosurgery scale [WFNS] or Hunt and Hess [HH] III-V), Fisher scale (III-IV), middle cerebral artery aneurysm location, severe vasospasm (clinic or angiography), cerebral infarct, and cerebral edema. The authors of the included studies were contacted due to missing data. The doubts were clarified by consensus.

\section{Risk of bias}

The modified Newcastle-Ottawa scale (NOS) ${ }^{7}$ was used for assessing the quality and risk of bias of the included studies. One reviewer (W.F.P.) assessed the risk of bias of each study using this scale and high, moderate, and low risk of bias were defined as NOS $<4$, between 4 and 6 , and $>6$, respectively, as in the original NOS. The risk of publication bias was further assessed using and comparing the

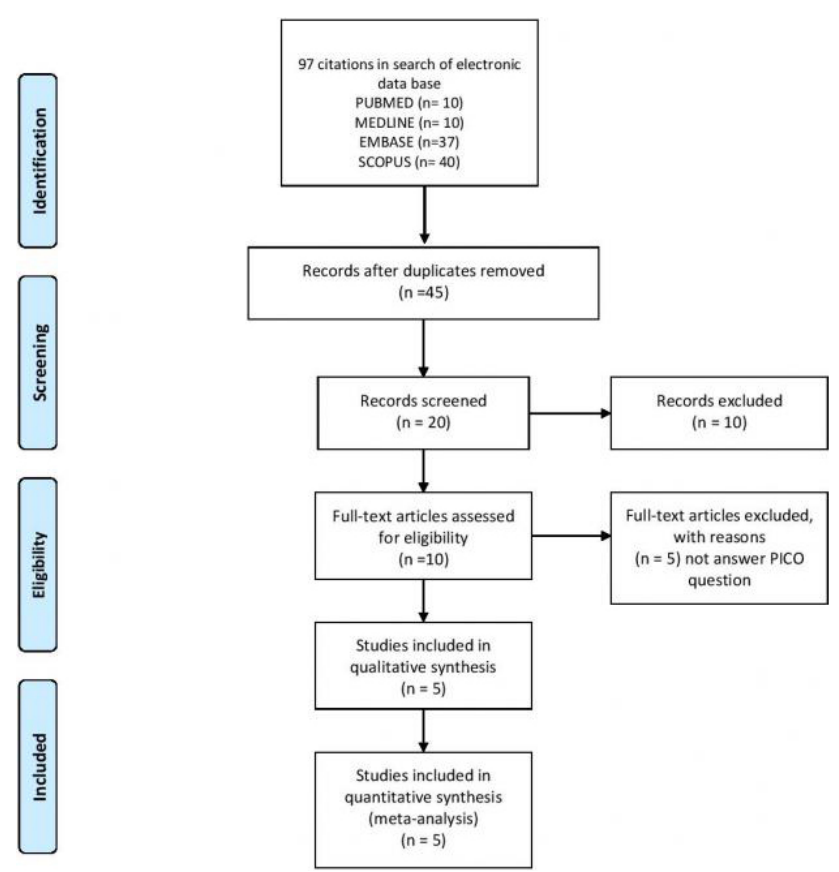

Figure 1. Preferred reporting items for systematic reviews and meta-analyses flowchart diagram. P, patient, problem or population; I, intervention; C, comparison, control or comparator; O, outcome(s). 
Egger's test. ${ }^{8}$ A p-value of less than 0.1 for Egger's test was considered statistically significant.

\section{Summary measures}

We analyzed the odds ratio (OR) of each of the predictive factors using the generic method of the inverse of the variance to combine these data. Some studies did not explicitly report them, which we calculated using the OR calculator of review manager.

\section{Synthesis of results}

Statistical analysis was performed through the odds ratio with generic inverse variance methodology for studies only reporting OR. Studies that do not report risk measures will be calculated with a fixed effect analysis model using RevMan 5.3 (Nordic Cochrane Centre, Copenhagen, Denmark). Heterogeneity was assessed by cal- culating chi-square $\left(\mathrm{I}^{2}\right)$, with high heterogeneity of the studies included in the analysis being above $60 \%$.

\section{IRB/ethics committee approval}

Meta-analyses do not require IRB review nor ethics committee approval.

\section{Results}

\section{Study selection}

After conducting the systematic search of the information following our strategy, 97 bibliographic citations were identified (PubMed 10, EMBASE 37, MEDLINE 10, Scopus 40). Of these 20 articles were considered potentially eligible based on the title or abstract, or both, and the full texts. After a review of the full text, 10 studies were con-

Table 1. Characteristics of included studies

\begin{tabular}{|c|c|c|c|c|}
\hline Study & Type & Patient & Risk factor (OR reported or calculate) & Length following \\
\hline Allen et al. $^{9}$ (2018) & $\begin{array}{l}\text { Retrospective cohort } \\
\text { study }\end{array}$ & $\begin{array}{l}282 \text { endovascular coiling } \\
(n=194) \\
\text { Neurosurgical clipping } \\
(n=88)\end{array}$ & $\begin{array}{l}\text { Sex female } \\
\text { Hunt and Hess IV-V } \\
\text { Fisher scale III-IV } \\
\text { Severe vasospasm by angiography } \\
\text { Cerebral edema (CT scan) } \\
\text { Cerebral Infarct (CT scan) }\end{array}$ & 3 months \\
\hline Byrne et al. ${ }^{10}(2003)$ & $\begin{array}{l}\text { Retrospective cohort } \\
\text { study }\end{array}$ & $\begin{array}{l}243 \text { all endovascular } \\
\text { coils embolization }\end{array}$ & $\begin{array}{l}\text { Age }>50 \text { years old } \\
\text { Sex female } \\
\text { WFNS III-VI } \\
\text { severe vasospasm by clinic or CT scan } \\
\text { cerebral edema (CT scan) } \\
\text { Middle cerebral artery aneurysm location }\end{array}$ & 6 months \\
\hline Hart et al. ${ }^{11}$ (2011) & $\begin{array}{l}\text { Prospective } \\
\text { randomized clinical } \\
\text { trial }\end{array}$ & $\begin{array}{l}235 \text { endovascular coiling } \\
(n=89) \\
\text { Neurosurgical clipping } \\
(n=146)\end{array}$ & $\begin{array}{l}\text { Age }>50 \text { years old } \\
\text { Sex female } \\
\text { WFNS III-VI } \\
\text { Fisher scale III-IV } \\
\text { Severe vasospasm by clinic or CT scan } \\
\text { Middle cerebral artery aneurysm location }\end{array}$ & 12 months \\
\hline $\begin{array}{l}\text { Molyneux et al. }{ }^{12} \\
(2005)^{*}\end{array}$ & $\begin{array}{l}\text { Prospective } \\
\text { randomized clinical } \\
\text { trial }\end{array}$ & $\begin{array}{l}2,143 \text { endovascular } \\
\text { coiling ( } n=1,073) \\
\text { Neurosurgical clipping } \\
(n=1,070)\end{array}$ & $\begin{array}{l}\text { Age }>50 \text { years old } \\
\text { Clinic severity (WNFS IV-V) } \\
\text { Fisher scale III-IV } \\
\text { Middle cerebral artery aneurysm location }\end{array}$ & $\begin{array}{l}12 \text { months to } \\
3 \text { years }\end{array}$ \\
\hline $\begin{array}{l}\text { Nathan et al. }{ }^{13} \\
(2018)\end{array}$ & $\begin{array}{l}\text { Retrospective cohort } \\
\text { study }\end{array}$ & $\begin{array}{l}174 \text { all Endovascular } \\
\text { coils }\end{array}$ & $\begin{array}{l}\text { Age }>50 \text { years old } \\
\text { Sex female } \\
\text { Hunt and Hess IV-V } \\
\text { Severe vasospasm (angiography and CT scan } \\
\text { or clinic) } \\
\text { Cerebral infarction (CT scan) } \\
\text { Cerebral edema (CT scan) } \\
\text { Middle cerebral artery aneurysm location }\end{array}$ & 6 months to 6 years \\
\hline
\end{tabular}

$C T$, computed tomography; WFNS, World Federation of Neurosurgery scale.

*We needed to contact to authors for missing or not reported data in the published article, but it was evaluated according to the methodology explained in the study. 
sidered eligible, five were ruled out because they did not meet the inclusion criteria and did not answer the research question, and five met the inclusion criteria for the review. ${ }^{9-13}$ The study selection process is shown in the PRISMA flow diagram as shown in (Fig. 1).

\section{Study characteristics}

From the studies included, three were retrospective cohort observational studies ${ }^{9,10,13}$ and two were prospective RCT. ${ }^{11,12}$ Characteristics of included studies are summarized in Table 1.

\section{Risk of bias}

Among the five included studies in the analysis, only one ${ }^{11} \mathrm{ob}$ tained the maximum score of 7 , two ${ }^{9,13}$ obtained 6 points, one ${ }^{12}$ obtained 5 points, and the remaining one ${ }^{10}$ obtained 4 of 7 points on the scale used (Table 2). The funnel plot and the Egger's test for all predictors showed different grades of asymmetry (Supplementary Fig. 1).

\section{Systematic review}

The cohort study by Allen et al. ${ }^{9}$ included 282 patients treated with coiling and 88 treated with clipping, who were recruited between 2010 and 2015. The selection was made using a confirmed aneurysmal source of SAH and managed with either endovascular coiling or surgical clipping. Patients were evaluated with $\mathrm{EEEG}$, recorded digitally in 115 patients (40\%) with suspicion of seizures. Moreover, 24 patients had seizures, 18 detected with CEEG and six based on clinical reports. Byrne et al. ${ }^{10}$ proposed that prophylactic use of antiepileptic drugs in patients diagnosed with subarachnoid

Table 2. NOS for quality assessment of studies included in this meta-analysis*

\begin{tabular}{|c|c|c|c|c|c|c|c|c|c|}
\hline Study & Study design & $\begin{array}{l}\text { Representativeness } \\
\text { of sample }\end{array}$ & $\begin{array}{c}\text { Size } \\
\text { sample }\end{array}$ & $\begin{array}{l}\text { Source of } \\
\text { information }\end{array}$ & $\begin{array}{l}\text { Demonstration } \\
\text { that outcome was not } \\
\text { present at study start }\end{array}$ & $\begin{array}{l}\text { Confusion } \\
\text { variable } \\
\text { control }\end{array}$ & $\begin{array}{l}\text { Assessment } \\
\text { of risk } \\
\text { factor }\end{array}$ & $\begin{array}{l}\text { Enough } \\
\text { follow-up } \\
\text { period }\end{array}$ & NOS \\
\hline $\begin{array}{l}\text { Allen et } \text { al. }^{9} \\
(2018)\end{array}$ & $\begin{array}{l}\text { Retrospective } \\
\text { cohort study }\end{array}$ & $\star$ & $\star$ & $\star$ & $\star$ & $\star$ & $\star$ & NA & $6 / 7$ \\
\hline $\begin{array}{l}\text { Byrne et al. }^{10} \\
(2003)\end{array}$ & $\begin{array}{l}\text { Retrospective } \\
\text { cohort study }\end{array}$ & $\star$ & $\star$ & NA & NA & $\star$ & NA & $\star$ & $4 / 7$ \\
\hline $\begin{array}{l}\text { Hart et al. }{ }^{11} \\
(2011)\end{array}$ & $\begin{array}{l}\text { Prospective } \\
\text { randomized } \\
\text { clinical trial }\end{array}$ & $\star$ & $\star$ & $\star$ & $\star$ & $\star$ & $\star$ & $\star$ & $7 / 7$ \\
\hline $\begin{array}{l}\text { Molyneux et } \\
\text { al. }^{12}(2005)\end{array}$ & $\begin{array}{l}\text { Prospective } \\
\text { randomized } \\
\text { clinical trial }\end{array}$ & $\star$ & $\star$ & NA & NA & $\star$ & $\star$ & $\star$ & $5 / 7$ \\
\hline $\begin{array}{l}\text { Nathan et } \\
\text { al. }^{13} \text { (2018) }\end{array}$ & $\begin{array}{l}\text { Retrospective } \\
\text { cohort study }\end{array}$ & $\star$ & NA & $\star$ & $\star$ & $\star$ & $\star$ & $\star$ & $6 / 7$ \\
\hline
\end{tabular}

NOS, Newcastle-Ottawa scale; NA, not applicable.

*Rated on a scale of 1 star to 7 stars.

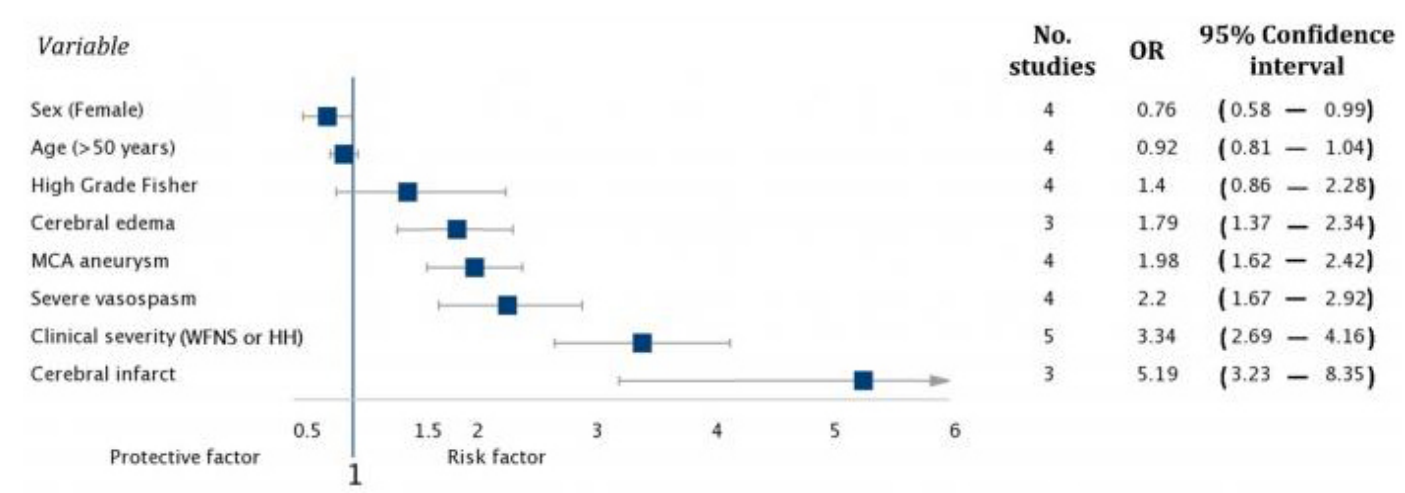

Figure 2. Odds ratios (ORs) for risk factors for seizures after endovascular treatment of ruptured intracranial aneurysms. MCA, middle cerebral artery; WFNS, World Federation of Neurosurgery scale; HH, Hunt and Hess. 
haemorrhage aneurysms treated with coil embolization was not justified due to the low incidence of seizures. Hart et al. ${ }^{11}$ used data from 43 centres, and the authors found that treatment with coiling significantly reduces the risk of seizures compared to surgical management. Furthermore, they reported that patients with middle cerebral artery aneurysms have a higher risk of seizures. Another study carried out by Molyneux et al.. ${ }^{12}$ The International Subarachnoid Aneurysm Trial, demonstrated that seizure frequency was $0.7 \%$ in the endovascular treated group compared to $12.9 \%$ in the neurosurgical treated group $(p=0.001)$. Lastly, an additional study by Nathan et al. ${ }^{13}$ showed that patients presenting subarachnoid haemorrhage with $\mathrm{HH}$ of 5 and severe vasospasm have an increased risk of in in-hospital seizures.

\section{Meta-analysis}

Five studies were chosen for the final analysis, involving 3,077 patients. The statistical analysis was performed according to standard protocol. Each variable was pooled in Figure 2. No significant differences in predictive factors such as higher Fisher's scale (III or IV) or greater age for the presence of seizures after a subarachnoid haemorrhage treated with coils both with a high $\mathrm{I}^{2}$ heterogeneity index of $62 \%$ and $79 \%$, respectively (Supplementary Figs. 2 and 3).

Being female was associated with a decrease in the risk of seizures (OR, 0.76; 95\% confidence interval [CI], 0.58-0.99; $p=0.04$ ) with adequate heterogeneity $\left(I^{2}=26 \%\right.$ ) (Supplementary Fig. 4). In this meta-analysis, we found that a high degree of severity scale (WFNS or $\mathrm{HH} \mathrm{III-V)} \mathrm{increases} \mathrm{the} \mathrm{risk} \mathrm{of} \mathrm{seizures} \mathrm{after} \mathrm{treatment} \mathrm{of} \mathrm{sub-}$ arachnoid haemorrhage with coils $(\mathrm{OR}, 3.34 ; 95 \% \mathrm{Cl}, 2.69-4.16$; $p<0.00001)$ with very high heterogeneity among the included studies $\left(I^{2}=98 \%\right)$. Probably, such high heterogeneity may influence the results for this risk factor (Supplementary Fig. 5).

The presence of severe vasospasm (detected in angiography, by clinical symptoms, or by imaging) increases the risk of seizures after embolization (OR, 2.20; 95\% Cl, 1.67-2.92; $p<0.00001)$ without heterogeneity among the studies analyzed $\left(I^{2}=0\right)$ (Supplementary Fig. 6). The subsequent development of cerebral infarction also increases the risk of seizures $(O R, 5.19 ; 95 \% \mathrm{Cl}, 3.23-8.35 ; p \leq$ $0.00001 ; 1^{2}=0 \%$ ) (Supplementary Fig. 7), cerebral edema (OR, 1.79; $95 \% \mathrm{Cl}, 1.37-2.34 ; p<0.0000 ; \mathrm{I}^{2}=64 \%$ ) with representative heterogeneity that could influence the results of this analysis (Supplementary Fig. 8), and the aneurysm located in the middle cerebral artery or its terminal branches (OR, 1.98; $95 \% \mathrm{Cl}, 1.62-2.42$; $p<0.00001 ; I^{2}=0 \%$ ) (Supplementary Fig. 9).

\section{Discussion}

The presence of seizures may play an important role in the outcome of patients with ruptured aneurysms. ${ }^{6}$ The results of this meta-analysis including 3,077 patients suggest that the risk of seizures in patients who undergo endovascular management of intracranial aneurysms is increased by a worse clinical severity (WFNS or $H H)$, severe vasospasm, cerebral infarction, and cerebral edema. Being female seemed to be a "protective" factor for seizures. Lastly, fisher grade and older age were not associated with increasing the risk of seizures after endovascular treatment of a ruptured intracranial aneurysm.

The mechanism associated with the development of seizures in this context is not clearly understood. Nonetheless, for endovascular procedures, seizures should be attributed to causes, which is different for the factors implicated in seizures after the microsurgical clipping. Nakagawa et al. ${ }^{14}$ reported delayed intracranial parenchymal changes in seven patients. Two of those nickel allergy was reported through skin patch testing, enforcing the theory of metal allergic reaction. ${ }^{14}$ Coil compression and foreign body have been either reported to produce transient changes in the nervous tissue. ${ }^{15}$ These changes, albeit transient, are capable to produce neurological deficits and have been termed as transient phenomena associated with neuro-intervention. ${ }^{16}$ These processes have, as common denominator, the inflammation, which have demonstrated to have an important role in epileptogenesis. Several inflammatory mediators (e.g., interleukin [IL]-1 $\beta$, tumor necrosis factor, IL-6, and PGE2) and the complement cascade play an active role in seizure generation. ${ }^{17}$ The reason that endovascular treatment leads to a cytokine-mediated pro-inflammatory state is a tough question to answer. Previously, it was reported that the nonionic iodinated contrast medium (widely used in endovascular procedures) can disrupt the blood-brain barrier and pour into the subarachnoid space. ${ }^{18}$ Subsequently, with the seizure, neuronal injury can arise because of postictal metabolic demands. In patients who develop seizures, the presence of hypotension and hypoxemia increases the risk of a secondary injury such as ischemic injury and ICP raise. ${ }^{19,20}$ Interestingly, Patankar and Hughes ${ }^{21}$ reported the resolution of temporal lobe epilepsy after coiling of intracranial aneurysms.

The association between seizures and clinical severity assessed through WFNS or HH scales could be explained with the association they have with brain tissue changes, such as cerebral infarction. ${ }^{22-24}$ Perhaps cerebral infarction and the underlying inflammatory compo- 
nent is guilty of the development of the seizures. This outcome of cerebral infarction could explain also the association with severe vasospasm by indirect relationship. ${ }^{25}$ Female sex has been linked to seizure threshold and frequency. ${ }^{26,27}$ Our results suggested that coiling may reduce the risk of seizure in women. One of the possible explanations is that patients with acute brain injury have low levels of melatonin. Naturally occurring, the antioxidant melatonin has shown an effect on oxidative stress and has a neuroprotective effect after a seizure. ${ }^{15}$ We believe that patients undergoing craniotomy experience altered melatonin levels that would be associated with neuronal injury, ischemia, and seizure, in contrast to coiling, in which surgical damage and surgical stress are very low.

The consistency of these findings across the included studies confirms the strong association of vasospasm after intracranial aneurysms rupture and the reduction in the risk of seizure in patients who underwent coil management. The duration of the bleeding-cerebral artery interaction has been established as determinants in the development of vasospasm. Thus, it has been advocated that early evacuation of the clot (before 48 hours) can reduce the risk of vasospasm. ${ }^{28,29}$ We consider that coiling can reduce vasospasm by reducing cerebral surgical manipulation and associating it with the use of measures such as lumbar drainage.

The ENACT trial demonstrated the potential use of Nerinetide in patients with ischemia after neurovascular management. Establishing neuroprotection strategies after intracranial aneurysm rupture is an attractive strategy. Seizures and vasospasm could be reduced with the development of neuroprotection strategies and demonstrates the great potential for further research in this area. ${ }^{30}$

\section{Summary of evidence}

This systematic review gives an overview of the available literature on the risk of seizure after embolization of intracranial aneurysms. This study only provides evidence $2 \mathrm{~A}$, due to the quality of the included studies.

\section{Limitations}

Some studies included in this analysis were retrospective. All articles included in this review were peer-reviewed. There was a possibility of publication bias. The inclusion of only articles in english could affect the generalization of our findings. Like any other study of a meta-analytical nature that uses pooled data without access to original patient data, it falls into another of our limitations. This is regard- ing not-published data. Besides, seizures may be under-reported especially in poor-grade patients with the limited examination. Furthermore, there is heterogeneity in the assessment of seizures and not all patients are routinely placed on continuous EEG. Some quite important studies where the authors did not respond to our inquire were excluded, and it is not sure whether these studied would had influenced this meta-analysis. Another limitation in our study is the absence of correlation between the temporal profile of seizure occurrence in aSAH in the included studies. Availability of data with respect to the incidence of seizure, during the onset of aSAH, immediate post intervention, recovery, and vasospasm, would have been more informative for evidence synthesis. Moreover, the included studies have incorporated data from both the endovascular intervention and microsurgical clipping. This results in heterogeneity in the studies and reduces the strength of the available evidence.

\section{Conclusion}

The results of this meta-analysis suggest that the risk of seizures in patients who underwent endovascular management of intracranial aneurysms is increased by a worse clinical severity (WFNS or $\mathrm{HH}$ ), severe vasospasm, cerebral infarction, and cerebral edema. The role of endovascular embolization and the risk of seizures is not completely understood, still missing evidence for how this type of neuro-intervention reduces the risk of seizure. In case of discovering a real risk of seizures, a prophylactic intervention should be studied, maybe a neuroprotector or an antiepileptic drug, which could have better the outcomes of patients who undergo an endovascular procedure. The correlation of the mechanism of coiling embolization and seizures requires more studies. Our study is an attempt to map the evidence available for seizure risk after endovascular intervention for aSAH and highlights the significant existing gaps in knowledge.

\section{References}

1. Suarez Jl, Tarr RW, Selman WR. Aneurysmal subarachnoid hemorrhage. N Engl J Med 2006;354:387-96.

2. Florez WA, García-Ballestas $E$, Deora $H$, et al. Intracranial hypertension in patients with aneurysmal subarachnoid hemorrhage: a systematic review and meta-analysis. Neurosurg Rev 2020 Feb 1. doi: 10.1007/ s10143-020-01248-9.

3. Lai LT, O'Donnell J, Morgan MK. The risk of seizures during the in-hospital admission for surgical or endovascular treatment of unruptured intracranial aneurysms. J Clin Neurosci 2013;20:1498-502. 
4. Claassen J, Peery S, Kreiter KT, et al. Predictors and clinical impact of epilepsy after subarachnoid hemorrhage. Neurology 2003;60:208-14.

5. Hoh BL, Nathoo S, Chi YY, Mocco J, Barker FG 2nd. Incidence of seizures or epilepsy after clipping or coiling of ruptured and unruptured cerebral aneurysms in the nationwide inpatient sample database: 2002-2007. Neurosurgery 2011;69:644-50.

6. O'Donnell JM, Morgan MK, Bervini D, Heller GZ, Assaad N. The risk of seizure after surgery for unruptured intracranial aneurysms: a prospective cohort study. Neurosurgery 2016;79:222-30.

7. Wells GA, Shea B, O'Connell $D$, et al. The Newcastle-Ottawa Scale (NOS) for assessing the quality of nonrandomised studies in meta-analyses [Internet]. Ottawa: The Ottawa Hospital Research Institute [cited 2020 Oct 14]. Available at: http://www.ohri.ca/programs/dinical_epidemiology/ oxford.asp.

8. Egger M, Davey Smith G, Schneider M, Minder C. Bias in meta-analysis detected by a simple, graphical test. BMJ 1997;315:629-34.

9. Allen $B B$, Forgacs $P B$, Fakhar MA, et al. Association of seizure occurrence with aneurysm treatment modality in aneurysmal subarachnoid hemorrhage patients. Neurocrit Care 2018;29:62-8.

10. Byrne JV, Boardman P, loannidis I, Adcock J, Traill Z. Seizures after aneurysmal subarachnoid hemorrhage treated with coil embolization. Neurosurgery 2003;52:545-52.

11. Hart Y, Sneade M, Birks J, Rischmiller J, Kerr R, Molyneux A. Epilepsy after subarachnoid hemorrhage: the frequency of seizures after clip occlusion or coil embolization of a ruptured cerebral aneurysm: results from the international subarachnoid aneurysm trial. J Neurosurg 2011;115:1159-68.

12. Molyneux AJ, Kerr RS, Yu LM, et al. International subarachnoid aneurysm trial (ISAT) of neurosurgical clipping versus endovascular coiling in 2143 patients with ruptured intracranial aneurysms: a randomised comparison of effects on survival, dependency, seizures, rebleeding, subgroups, and aneurysm occlusion. Lancet 2005;366:809-17.

13. Nathan SK, Brahme IS, Kashkoush Al, Anetakis K, Jankowitz BT, Thirumala PD. Risk factors for in-hospital seizures and new-onset epilepsy in coil embolization of aneurysmal subarachnoid hemorrhage. World Neurosurg 2018;115:e523-31.

14. Nakagawa I, Park HS, Kotsugi M, et al. Delayed intracranial parenchymal changes after aneurysmal coil embolization procedures for unruptured intracranial aneurysms. Oper Neurosurg (Hagerstown) 2020;19:76-83.

15. Cruz JP, Marotta T, O'Kelly $C$, et al. Enhancing brain lesions after endovascular treatment of aneurysms. AJNR Am J Neuroradio/ 2014;35:1954-8.

16. Garcia-Ballestas E, Martinez-Perez R, Al-Dahir M, Agrawal A, Moscote-Salazar LR. Letter: delayed intracranial parenchymal changes after aneurysmal coil embolization procedures for unruptured intracranial aneurysms. Oper Neurosurg (Hagerstown) 2020;19:E99-100.

17. Vezzani A, French J, Bartfai T, Baram TZ. The role of inflammation in epilepsy. Nat Rev Neurol 2011;7:31-40.

18. Uchiyama $Y$, Abe $T$, Hirohata $M$, et al. Blood brain-barrier disruption of nonionic iodinated contrast medium following coil embolization of a ruptured intracerebral aneurysm. AJNR Am J Neuroradiol 2004;25: 1783-6.

19. Vespa P, Martin NA, Nenov $V$, et al. Delayed increase in extracellular glycerol with post-traumatic electrographic epileptic activity: support for the theory that seizures induce secondary injury. Acta Neurochir Supp/ 2002;81:355-7.

20. Sampson TR, Dhar R, Zipfel GJ. Cerebral infarction following a seizure in a patient with subarachnoid hemorrhage complicated by delayed cerebral ischemia. Surg Neurol Int 2011;2:14.

21. Patankar T, Hughes D. Resolution of temporal lobe epilepsy and MRI abnormalities after coiling of a cerebral aneurysm. A $R$ R Am J Roentgenol 2005; 185:1664-5.

22. Rabinstein AA, Friedman JA, Weigand SD, et al. Predictors of cerebral infarction in aneurysmal subarachnoid hemorrhage. Stroke 2004;35: 1862-6.

23. Konczalla J, Seifert $V$, Beck J, et al. Outcome after hunt and hess grade $\checkmark$ subarachnoid hemorrhage: a comparison of pre-coiling era (1980-1995) versus post-ISAT era (2005-2014). J Neurosurg 2018;128: 100-10.

24. Brami J, Chousterman B, Boulouis G, et al. Delayed cerebral infarction is systematically associated with a cerebral vasospasm of large intracranial arteries. Neurosurgery 2020;86:E175-83.

25. Jaja BN, Lingsma $H$, Schweizer TA, et al. Prognostic value of premorbid hypertension and neurological status in aneurysmal subarachnoid hemorrhage: pooled analyses of individual patient data in the SAHIT repository. J Neurosurg 2015;122:644-52.

26. Bangar S, Shastri A, El-Sayeh H, Cavanna AE. Women with epilepsy: clinically relevant issues. Funct Neurol 2016;31:127-34.

27. Zoghi M, Vaseghi B, Bastani A, Jaberzadeh S, Galea MP. The effects of sex hormonal fluctuations during menstrual cycle on cortical excitability and manual dexterity (a pilot study). PLoS One 2015;10:e0136081.

28. Fisher CM, Kistler JP, Davis JM. Relation of cerebral vasospasm to subarachnoid hemorrhage visualized by computerized tomographic scanning. Neurosurgery 1980;6:1-9.

29. Nosko M, Weir BK, Lunt A, Grace M, Allen P, Mielke B. Effect of clot removal at 24 hours on chronic vasospasm after SAH in the primate model. J Neurosurg 1987;66:416-22.

30. Hill MD, Martin RH, Mikulis $D$, et al. Safety and efficacy of NA-1 in patients with iatrogenic stroke after endovascular aneurysm repair (ENACT): a phase 2, randomised, double-blind, placebo-controlled trial. Lancet Neurol 2012;11:942-50. 
Supplementary Material 1. Full Literature Search on PubMed, EMBASE and Scopus for studies assessing the risk of seizure after the endovascular treatment of ruptured intracranial aneurysm.

PubMed/ MEDLINE (("seizures"[MeSH Terms] OR "seizures"[All Fields]) OR ("seizures"[MeSH Terms] OR "seizures"[All Fields] OR "convulsion"[All Fields])) AND ("intracranial aneurysm"[MeSH Terms] OR ("intracranial"[All Fields] AND "aneurysm"[All Fields]) OR "intracranial aneurysm"[All Fields] OR ("brain"[All Fields] AND "aneurysm"[All Fields]) OR "brain aneurysm"[All Fields]) AND ((Clinical Trial[ptyp] OR Observational Study[ptyp]) AND "humans"[MeSH Terms])

EMBASE

(("seizures"[MeSH Terms] OR "seizures"[All Fields]) OR ("seizures"[MeSH Terms] OR "seizures"[All Fields] OR "convulsion"[All Fields])) AND (("intracranial aneurysm"[MeSH Terms] OR ("intracranial"[All Fields] AND "aneurysm"[All Fields]) OR "intracranial aneurysm"[All Fields] OR ("brain"[All Fields] AND "aneurysm"[All Fields]) OR "brain aneurysm"[All Fields]) AND ( coils[All Fields] AND ("embolization, therapeutic"[MeSH Terms] OR ("embolization"[All Fields] AND "therapeutic"[All Fields]) OR "therapeutic embolization"[All Fields] OR "embolization"[All Fields]))

Scopus

(("seizures"[MeSH Terms] OR "seizures"[All Fields]) OR ("seizures"[MeSH Terms] OR "seizures"[All Fields] OR "convulsion"[All Fields])) AND ("intracranial aneurysm"[MeSH Terms] OR ("intracranial "[All Fields] AND "aneurysm"[All Fields]) OR "intracranial aneurysm"[All Fields] OR ("brain"[All Fields] AND "aneurysm"[All Fields]) OR "brain aneurysm"[All Fields]) 
A
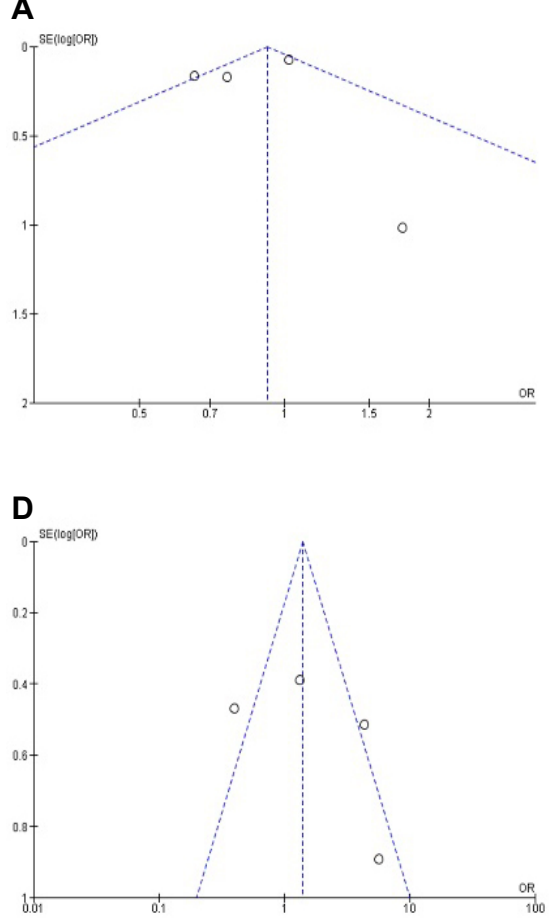

B
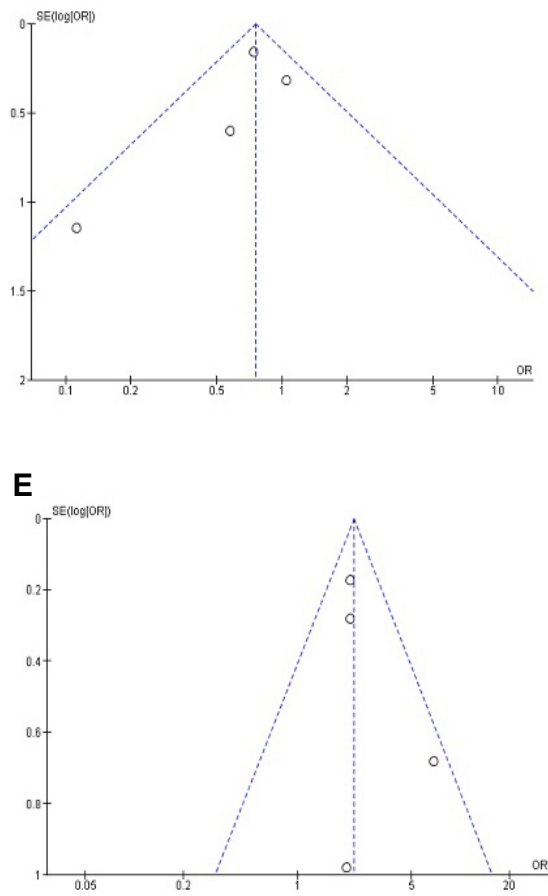

C
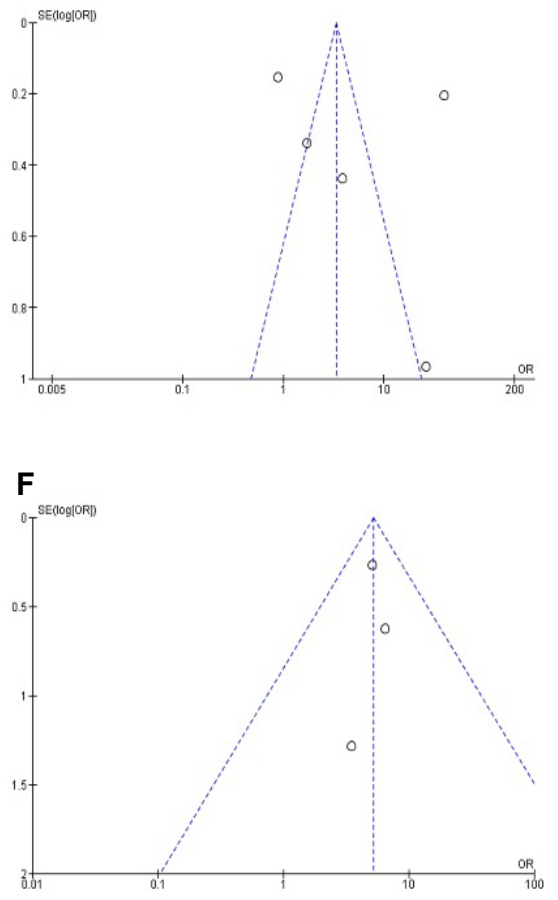

Supplementary Figure 1. (A-F) Funnel plot evaluating for publication bias. 
Odds Ratio

Study or Subgroup log[Odds Ratio]

Byrne 2003

Hart 2011

Molyneux 2005

Nathan 2018

Total $(\mathbf{9 5} \% \mathrm{Cl})$

Heterogeneity: $\mathrm{Chi}^{2}=7.90, \mathrm{df}=3(\mathrm{P}=0.05) ; \mathrm{I}^{2}=62 \%$

Test for overall effect: $Z=1.32(P=0.19)$
Odds Ratio

IV, Fixed, 95\% Cl

$\begin{array}{llll}-0.2744 & 0.1744 & 13.3 \% & 0.76[0.54,1.07]\end{array}$

$\begin{array}{llll}-0.4308 & 0.1654 & 14.8 \% & 0.65[0.47,0.90]\end{array}$

$\begin{array}{llll}0.566 & 1.016 & 0.4 \% & 1.76[0.24,12.90]\end{array}$

$0.0198 \quad 0.0753 \quad 71.5 \% \quad 1.02[0.88,1.18]$

$100.0 \% \quad 0.92[0.81,1.04]$

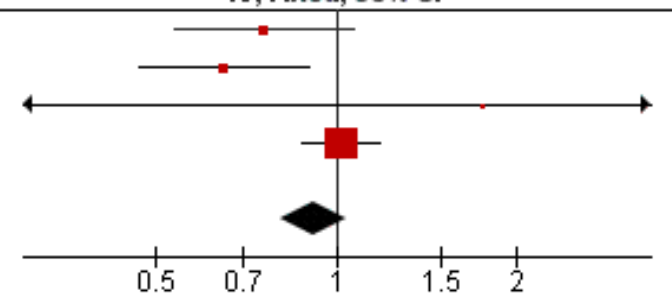

Supplementary Figure 2 . Forest plot for age $>50$ years old as a risk factor of seizures after ruptured intracranial aneurysm treated with coils embolization. $\mathrm{SE}$, standard error; $\mathrm{Cl}$, confidence interval. 


\section{Odds Ratio}

Study or Subgroup log[Odds Ratio]

Allen 2018

Byrne 2003

Hart 2011

Nathan 2018

Total $(\mathbf{9 5} \% \mathrm{Cl})$

Heterogeneity

Test for overall effect: $Z=2.01(P=0.04)$
SE Weight IV, Fixed, 95\% Cl

Odds Ratio

IV, Fixed, 95\% Cl

$\begin{array}{llll}-0.5539 & 0.6058 & 5.2 \% & 0.57[0.18,1.88]\end{array}$

$\begin{array}{llll}0.0488 & 0.3207 & 18.5 \% & 1.05[0.56,1.97]\end{array}$

$\begin{array}{llll}-0.3031 & 0.1597 & 74.8 \% & 0.74[0.54,1.01]\end{array}$

$\left.\begin{array}{llll}-2.1919 & 1.1484 & 1.4 \% & 0.11[0.01,1.06\end{array}\right]$

$100.0 \% \quad 0.76[0.58,0.99]$

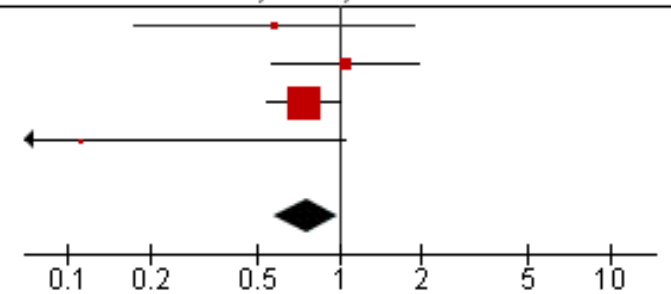

Supplementary Figure 3. Forest plot for sex (female) as a risk factor of seizures after ruptured intracranial aneurysm treated with coils embolization. SE, standard error; $\mathrm{Cl}$, confidence interval. 


\begin{tabular}{|c|c|c|c|c|c|c|c|c|}
\hline Study or Subgroup & log[Odds Ratio] & SE & Weight & $\begin{array}{l}\text { Odds Ratio } \\
\text { IN, Fixed, } 95 \% \text { CI }\end{array}$ & \multicolumn{4}{|c|}{$\begin{array}{c}\text { Odds Ratio } \\
\text { IV, Fixed, } 95 \% \text { CI }\end{array}$} \\
\hline Allen 2018 & 3.6805 & 0.2053 & $29.4 \%$ & $39.67[26.53,59.32]$ & & & & $\rightarrow-$ \\
\hline Byrne 2003 & -0.1258 & 0.1546 & $51.9 \%$ & $0.88[0.65,1.19]$ & & & & \\
\hline Hart 2011 & 0.5346 & 0.338 & $10.9 \%$ & $1.71[0.88,3.31]$ & & & $\rightarrow$ & \\
\hline Molyneux 2005 & 1.3471 & 0.4385 & $6.5 \%$ & $3.85[1.63,9.08]$ & & & & \\
\hline Nathan 2018 & 3.2649 & 0.9649 & $1.3 \%$ & $26.18[3.95,173.48]$ & & & & \\
\hline Total $(95 \% \mathrm{Cl})$ & & & $100.0 \%$ & $3.34[2.69,4.16]$ & & & $\boldsymbol{\varphi}$ & \\
\hline $\begin{array}{l}\text { Heterogeneity: Chi } \\
\text { Test for overall effect }\end{array}$ & $\begin{array}{l}228.09, d f=4(P \leq \\
Z=10.83(P<0.00\end{array}$ & $\begin{array}{l}=0.00001) \\
(0001)\end{array}$ & $;\left.\right|^{2}=98 \%$ & & 0.005 & 0.1 & 10 & $\frac{1}{200}$ \\
\hline
\end{tabular}


Odds Ratio

Study or Subgroup $\quad \log [$ Odds Ratio] $\quad$ SE Weight $\quad$ IV, Fixed, 95\% C

Allen 2018

Hart 2011

Molyneux 2005

Nathan 2018

Total $(\mathbf{9 5} \% \mathrm{Cl})$

Heterogeneity: $\mathrm{Chi}^{2}=14.43, \mathrm{df}=3(\mathrm{P}=0.002) ; \mathrm{I}^{2}=79 \%$

Test for overall effect: $Z=1.36(P=0.18)$

$\begin{array}{llll}1.7346 & 0.8922 & 7.8 \% & 5.67\end{array}[0.99,32.57]$

$\begin{array}{llll}-0.9163 & 0.469 & 28.1 \% & 0.40[0.16,1.00]\end{array}$

$\begin{array}{llll}1.4633 & 0.5132 & 23.5 \% & 4.32\end{array}[1.58,11.81]$

$100.0 \% \quad 1.40[0.86,2.28]$
Odds Ratio

IV, Fixed, 95\% Cl

$\begin{array}{llll}0.2864 & 0.39 & 40.6 \% & 1.33[0.62,2.86]\end{array}$

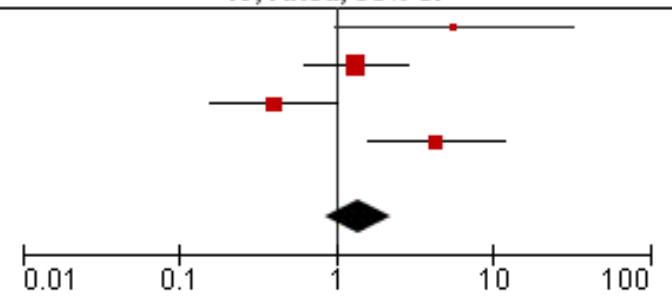

Supplementary Figure 5. Forest plot for Fisher scale (computed tomography scan) as a risk factor of seizures after ruptured intracranial aneurysm treated with coils embolization. SE, standard error; $\mathrm{Cl}$, confidence interval. 
Odds Ratio

Study or Subgroup $\quad \log [$ Odds Ratio] $\quad$ SE Weight $\quad$ IV, Fixed, 95\% C

Allen 2018

Byrne 2003

Hart 2011

Nathan 2018

Total $(95 \% \mathrm{Cl})$

Total (95\% CI)

Heterogeneity: $\mathrm{Chi}^{2}=2.92, \mathrm{df}=3(\mathrm{P}=0.40) ; \mathrm{I}^{2}=0 \%$

Test for overall effect: $Z=5.54(P \leq 0.00001)$
Odds Ratio

IV, Fixed, $95 \% \mathrm{Cl}$

$\begin{array}{rrrr}0.6931 & 0.98 & 2.1 \% & 2.00[0.29,13.65] \\ 0.7419 & 0.2813 & 25.7 \% & 2.10[1.21,3.64] \\ 0.7386 & 0.1734 & 67.7 \% & 2.09[1.49,2.94] \\ 1.9286 & 0.6813 & 4.4 \% & 6.88[1.81,26.15] \\ & & & \\ & & 100.0 \% & 2.20[1.67,2.92]\end{array}$

$2.20[1.67,2.92]$

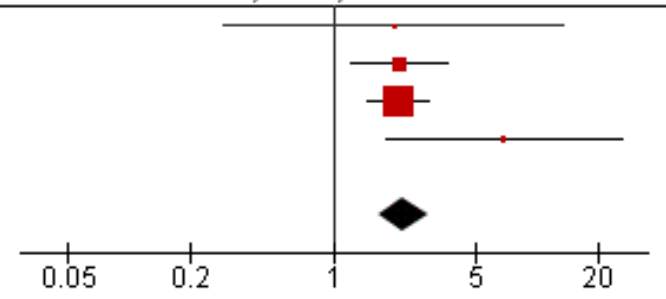

Supplementary Figure 6. Forest plot for severe vasospasm (angiography or computed tomography scan) as a risk factor of seizures after ruptured intracranial aneurysm treated with coils embolization. SE, standard error; Cl, confidence interval. 
Odds Ratio

Study or Subgroup log[Odds Ratio] $\quad$ SE Weight $\quad$ IV, Fixed, $95 \% \mathrm{Cl}$
Allen 2018

Hart 2011

Nathan 2018

1.2528

1.2817

$1.6253 \quad 0.2687$

$\begin{array}{lll}1.861 & 0.6274\end{array}$

Total (95\% Cl)

Heterogeneity: $\mathrm{Chi}^{2}=0.22, \mathrm{df}=2(\mathrm{P}=0.90) ; \mathrm{I}^{2}=0 \%$

Test for overall effect: $Z=6.79(P<0.00001)$
Odds Ratio

IV, Fixed, $95 \% \mathrm{Cl}$

Supplementary Figure 7. Forest plot for cerebral infarction as a risk factor of seizures after ruptured intracranial aneurysm treated with coils embolization. SE, standard error; $\mathrm{Cl}$, confidence interval. 
Odds Ratio

Study or Subgroup log[Odds Ratio] SE Weight IV, Fixed, 95\% CI

Allen 2018

Byrne 2003

Nathan 2018

Total $(95 \% \mathrm{Cl})$

Heterogeneity: $\mathrm{Chi}^{2}=5.63, \mathrm{df}=2(\mathrm{P}=0.06) ; \mathrm{I}^{2}=64 \%$

Test for overall effect: $Z=4.27(P \leq 0.0001)$

$\begin{array}{llll}0.4187 & 0.1558 & 76.5 \% & 1.52[1.12,2.06]\end{array}$
Odds Ratio

IV, Fixed, 95\% Cl

$\begin{array}{lllll}0.7793 & 0.4402 & 9.6 \% & 2.18[0.92,5.17]\end{array}$

$\begin{array}{llll}1.3429 & 0.3658 & 13.9 \% & 3.83\end{array}[1.87,7.84]$

$100.0 \% \quad 1.79[1.37,2.34]$

Supplementary Figure 8 . Forest plot for cerebratedema

Supplementary Figure 8. Forest plot for cerebral edema (computed tomography) as a risk factor of seizures after ruptured intracranial aneurysm treated with coils embolization. SE, standard error; Cl, confidence interval. 
Odds Ratio

Study or Subgroup log[Odds Ratio] $\quad$ SE Weight $\quad$ IV, Fixed, 95\% Cl

$0.8024 \quad 0.1793$

$56.2 \% \quad 1.83[1.40,2.39]$

$32.6 \% 2.23[1.57,3.17]$

$8.3 \% \quad 2.23[1.11,4.49]$
Byrne 2003

Hart 2011

Molyneux 2005

Nathan 2018

0.6043

0.1367

$0.803 \quad 0.3566$

$0.571 \quad 0.5963$

Total $(\mathbf{9 5} \% \mathrm{Cl})$

Heterogeneity: $\mathrm{Chi}^{2}=0.92, \mathrm{df}=3(\mathrm{P}=0.82) ; \mathrm{I}^{2}=0 \%$

Test for overall effect: $Z=6.68$ ( $P \leq 0.00001$ )
Odds Ratio IV, Fixed, 95\% Cl

$3.0 \% 1.77[0.55,5.70]$

$100.0 \% \quad 1.98[1.62,2.42]$

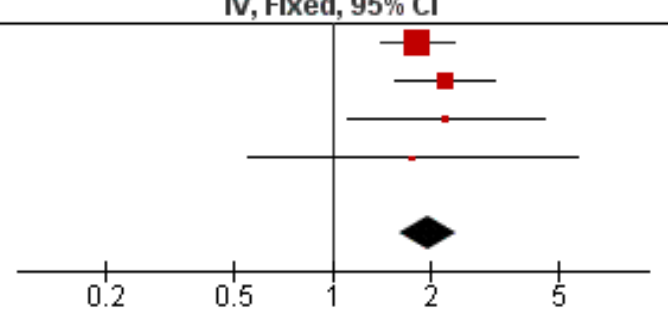

Supplementary Figure 9. Forest plot for aneurysm located in middle cerebral artery as a risk factor of seizures after ruptured intracranial aneurysm treated with coils embolization. SE, standard error; $\mathrm{Cl}$, confidence interval. 